\title{
First report of ashwagandha damping-off caused by Rhizoctonia solani Kühn AG - 2- 2 in Uttar Pradesh, India
}

\author{
Arvind Saroj ${ }^{1} \cdot$ Abdul Samad $^{1}$ \\ Received: 30 January 2018 / Accepted: 3 June 2019 / Published online: 18 June 2019 \\ (C) Società Italiana di Patologia Vegetale (S.I.Pa.V.) 2019
}

Keywords Ashwagandha $\cdot$ Damping off $\cdot$ Rhizoctonia solani $\cdot$ Fungal pathogen

Ashwagandha (Withania somnifera) is cultivated commercially for glycowithanolides rich roots in India. In January 2016, symptoms of damping-off such as water-soaked, necrotic lesions on the basal stem were observed on ashwagandha seedlings, approximately $30 \%$. Isolation was carried out from infected parts, cut into small pieces, surface sterilized with $1 \%$ sodium hypochlorite for $1 \mathrm{~min}$, rinsed thrice with sterile distilled water, placed on potato dextrose agar (PDA) plates and incubated at $28^{\circ} \mathrm{C}$ for five days. Pure fungal colonies were dark brown with abundant sclerotia, hyphae branch at right angles, with distinct constriction at the origin of branching, a septum near the originating point of the hyphal branch, and hyphae were multinucleate. The fungus was morphologically identified as Rhizoctonia solani Kühn (Sneh et al. 1991). The isolate showed a C2 type anastomosis reaction with tester strain $R$. solani Kühn AG 2 provided by Dr. Kuninga, Hokkaido, Japan (Carling 1996). The internal transcribed spacer (ITS) region was sequenced using universal primers ITS1/ITS4 (White et al. 1990). The sequence was deposited in GenBank with accession No. KX397678, blast analysis revealed 100\% identity with a R. solani AG 2-2 strain (KF907728). Ashwagandha seedlings were grown in small earthen pots using autoclaved soil, 15 sclerotia were added/pot, while pots without inoculum served as a control. Both inoculated and

Abdul Samad

samad_cimap@yahoo.co.in

1 Department of Plant Pathology, CSIR- Central Institute of Medicinal and Aromatic Plants (CIMAP), Lucknow 226015, India non-inoculated seedlings were kept in a glasshouse at $28 \pm$ $2{ }^{\circ} \mathrm{C}$ with $80 \%$ relative humidity. The same symptoms as observed in field appeared within 2 days. Identification of the re-isolated pathogen using molecular technique and anastomosis reaction with tester strain as well as isolated pathogen fulfilled the Koch's postulates. The $R$. solani was earlier reported as epiphyte on ashwagandha (Krishnamurthy et al. 2008). To the best of our knowledge, this is the first report of damping-off caused by $R$. solani Kühn AG 2-2 on ashwagandha in Uttar Pradesh, India.

\section{References}

Carling DE (1996) Grouping in Rhizoctonia solani by hyphal anastomosis reaction. In: Sneh B, Jabaji-Hare S, Neat S, Dijst G, et al. (Eds.), Rhizoctonia Species: Taxonomy, Molecular Biology, Ecology, Pathology and Disease Control. Kluwer Academic Publishers, Dordecht, $37-47$

Krishnamurthy YL, Naik SB, Jayaram S (2008) Fungal communities in herbaceous medicinal plants from the Malnad region, southern India. Microbes Environ 23(1):24-28

Sneh B, Burpee L, Ogoshi A (1991) Identification of Rhizoctonia species. American Phytopathological Society Press, St. Paul

White TJ, Bruns T, Taylor J (1990) PCR Protocols: A Guide to Methods and Applications. MA Innis et al., eds. Academic Press, San Diego, CA, USA

Publisher's note Springer Nature remains neutral with regard to jurisdictional claims in published maps and institutional affiliations. 